\title{
CHANGE MANAGEMENT AT TERTIARY LEVEL EDUCATION: A COMPARISON OF PRIVATE AND PUBLIC SECTOR INSTITUTIONS
}

\author{
Sehrish Kashan \\ Ph.D. Scholar, Department of Education, \\ National University of Modern Languages, Islamabad \\ sehrishedu@yahoo.com \\ Wajeeha Aurangzeb \\ Associate Professor, Department of Education, \\ National University of Modern Languages, Islamabad \\ waurangzeb@numl.edu.pk
}

\begin{abstract}
Managing change is an overwhelming task at tertiary level education. With increasing pressure to enhance quality and student outcomes, it can be often difficult to deal with the changes that have a significant impact on the performance of any institution. This study aimed to determine the perceptions of teaching faculty regarding change management at the university level and to determine the difference in perceptions of faculty members based on sector i.e. public and private sector universities of Punjab. The present study was descriptive in nature. The study adopted the quantitative design and data collection phase consisted of a sample of 536 faculty members. $20 \%$ faculty of social sciences were selected by using a proportional stratified sampling technique. The researcher developed a questionnaire containing a five-point Likert Scale based on Fullan's Educational Change Model (2016), reviewed literature, and related studies. The researcher used a validated and reliable questionnaire for data collection. Findings revealed that change initiatives lead to student learning outcomes. The new initiatives pointed to enhance faculty morale. A significant difference was found among faculty members by sector (public and private) regarding their perceptions. The perceptions of both public and private sector faculty members were found better aligned with Fullan's Educational Change Model. Based on the findings of the study, it is recommended that at the university level the administrators implement a continuous improvement approach, make clear plans, use concentration, emphasize culture building, and a better approach to research.
\end{abstract}

Keyword: Educational Change Management, Fullan's Educational Change Model, Comparison, Tertiary level education.

\section{INTRODUCTION}

Change is an inconsistent and responsive process. Change must be accepted by every single person in the institutes, as to get wide-ranged experiences of this area, employees should be ready for change but their acceptance towards change is very important. Along with education change is also essential for human development. Change along with knowledge and exploration plays a vital role in human life and its surroundings. The results of change not only provide more opportunities for human development but also enhance its education and exploration. As a leader, one can also focus on change and changes that are taking place in human impact. (Brix \& Peters, 2015).

Change management focuses more on identities people their ways of interaction. Therefore, being visionary change agents, leaders will be required to be more skillful and motivational. Transformation in education occurred in various forms, in different times, and in various regions with diverse activities held in the political, social, and cultural vessel that has been the main topic of wideranged research-related projects of several individuals. Change management is important for the growth of any organization. It is introduced as a ground of study with the help of a well-known and increasing number of involvement and projects on research in the field of educational change. (Hayes, 2018).

Sawitri et al. (2015) added few more suggestions in favor of employees' readiness to accept a change that there are three main points which put a positive effect on this acceptance: factors related to the workplace, relation of employees with management, especially, their skills, knowledge of the job and its requirements. Employees are very important for any organization and they are the roots of 
that organization. Therefore, employees must practice these changes as with the help of these practices they would be able to generate a positive attitude towards the institutions. Changes that are held on institutional grounds are needed to be implemented with the help of workers' willingness and their favor towards the change of program which the institutes have suggested so that the effective implementation of the program will be done. Employees' readiness is a necessary part of the change.

According to Scott et al. (2016) every single person who works in the institutes has different viewpoints about new changes which occur at an institutional level, as they have different experiences about life, their motivation level is different from one another, additionally, there are several stages of knowledge, values and behavior patterns, supporting system, so it is quite difficult in institutes to implement new changes with such individualities.

Having similar ideas integrated them after writing regarding the organizational model in association with the prospect on the process of change. In their argument, they stress the point that the organizations contain a culture and structure where people participate in activities using control and techs. Two organizational models were discussed by them, first model was named the systems model, this model can be well described by mechanical or scientific or bureaucratic or traditional. While the second model is cultural. The systems model is based on hierarchical, bureaucratic, and strong administrative structures, as it's believed to be reasonable, balanced as well supplement along with using the information, which is measurable, in way of input/output linear procedure of action operation (Verhulst \& Lambrechts, 2015).

Due to its direct, 'tidy' and stubborn nature, the scientific approach is being criticized. There is an assumption for it that its goals, constructions, and orderliness in relationship with the organization do not exist essentially. Moreover, the growing awareness towards the significance of the particular context of the organization raised questions for this approach, and criticism from the people who found change management a complex and effective procedure as a sensitive framework was formed by Cummings, Bridgman \& Brown (2016) the change model, termed as 'procession'. These schematic change models were also criticized by McGrath et al. (2016) that analyze the change in the organization logically, an approach which is a chronological planning process and change of management, moreover, having positive and traditional tone usually and are named as 'undersocialized ones.'

For change management in education, the above-mentioned key factors are essential. Keeping in view the suggestions of Ghavifekr, Afshari, Siraj \& Razak (2017), social aspects, for example, regulate, feeling, politics, and human understanding, in the actual world, are permitted to interfere, it is to be admitted that regarding our valued strategy for future if planning would be done wisely then still, we could not be confident on controlling aims, concepts, desires, determinations, and attitudes of people. Consequently, the change procedures are very complex, even become more and unmanageable in comparison with realists' approach to changing management.

\section{The Concept of Educational Change}

Educational change has been described by Hornstein, (2015) with multiple angles making various images of change. In addition, with the help of these images change can be imagined as a product or a procedure, intended procedures outcomes, or the outcomes of unintended procedures, it's possible that change can be specific or combined, probably the outcomes are organizational change or maybe partial, it can be a set of different levels or an incident only, perhaps, it can be valid locally and worldly or unanimously and can be steady or be sudden. According to Doppet (2017), change is a variable and a specific procedure of change can be formed by diverse factors, such as, the elements of change which are scale and form, the politics of change that includes social disputes, influences/forces, conferences, in the end, change context.

The concept of educational change by Hornstein, (2015) and general change by Dawson; if both the notions are perceived collectively then the outcomes would be like, the strong factors of change as discussed earlier: the substance, politics, and context, can form the precise sketch of change in a specific context. On the other hand, aside from a sequence of imageries, considering change a broader field as it can cover a wide-ranging idea in relation with the development, mainly about regeneration, progression, and transformation. The term 'change' has a wide range in its meaning, which forms it a complex fact, there are many researchers who have called it a complex 
social fact, instead, they stated that it's not a habit, procedural, linear entirely, and not even process of a program (Da Veiga, 2018).

Following the statement of Dana (2016) the concept of change is truly an activity that is technocratic and logical, it could be instructive with a straight thought over and headed towards results that can be assessable, it is the activity that is being challenged progressively and found misguiding.

Razzaq (2012) stated that even though a detailed and timely reply is asked from the educational systems for social and technological changes, furthermore she added to the statement that perhaps, change can begin from inwardly formed transformation as well. For multiple causes, change can be formed, for example, individual positions of the one who begins or demand a change; personal interests of bureaucratic; ready to get chance but unfulfilled desires presently; reviewing external sources, etc. Consequently, there can be various educational changes which include, innovative legislation, examination, staff influences, students and parents, latest development technology (Salawana, 2019).

\section{Technological Changes}

Following Razzaq's (2012) views, from the educational system, a detailed and in time response is demanded from industrial and social changes, as Bush \& Coleman (2000) defined that it can be generated through internal innovation.' According to Law \& Glover (2000), for numerous causes change can be introduced or started, like individual positions of the people who are about to generate change or in demand of it, personal interests of bureaucratic, in concern with meeting the expected needs that are unfulfilled presently, or in demand of external sources and so forth. As discussed by Salawana (2019), there can be various sources of educational change which comprises of inspection of new legislation, staff's, students' and parents' pressure, and development of latest technology. Furthermore, they mentioned that the concept of change which is fundamentally logical, a technocratic activity that can be instructed is considered clearly and leads towards the assessable results, but it's being challenged ever more and mislead as well.

\section{Structural changes}

Many researchers consider change as fake or profound. According to, Ramos et al. (2015) change can be enhanced or fundamental, Vähäsantanen (2015) stated that it can be first-order change or secondorder change. The first-order change which is superficial or enhanced as well can never be effective to roles, structure, and culture. Therefore, the second-order change which is profound or fundamental as well mainly concentrates on the transformation of structures, roles, goals, and culture. Following Finnan and Levin's (2000) viewpoints, the actual and constant change never happened until the change in fundamental views and assumptions happened. For an educational change, the difference between actual and profound change and enhancing and artificial change has peculiar implications. In an argument of Fullan \& Levin (2009), it has been discussed that it is obligatory to know the change's sources and purposes, to understand the educational change and asserts which has generally focused on first-order change that exists, to improve change, instead of second-order change which changes the basics. Though, second-order change can never be an end itself.

\section{Importance of Change Management}

1. Due to a purpose, we change.

2. For an individual change, organizational change is required.

3. Organizational results are the joint results of change in the individual.

4. To manage change in people, change management is an empowering framework.

\section{Fullan's Educational Change model of three-phase Change Process}

Initiation, implementation, and continuation are three change management phases that are proposed by Fullan (2016), known as Fullan's Educational Change Model (2016). 


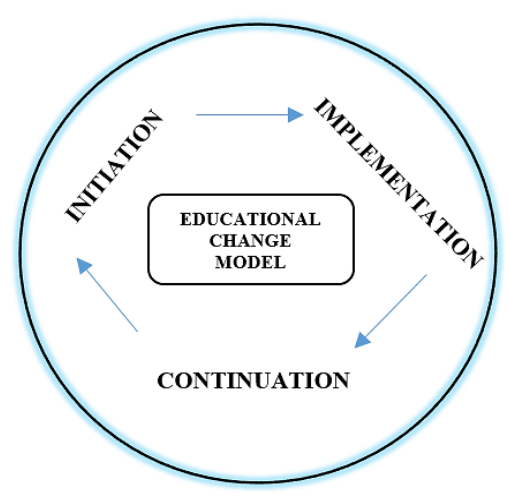

Figure 1: Educational Change Model (Fullan, 2016)

The latest Fullan's (2016) model of the change management process includes three phases. Initiation Phase; this phase indicates the start of the change process. When administrators or external agency initiates or starts a particular program. Secondly, the Implementation Phase indicates the deployment of change management and employees are encouraged to use selected practices. In the Continuation Phase which is also called the evaluation phase, new practices are continued with the passage of time. Outcomes are also evaluated in this phase which provides the view of the effectiveness of change initiatives.

\section{Research Questions}

1. What is the status of change management at the tertiary level?

2. Is there any sector base difference in change management at the tertiary level?

\section{Objectives of the Study}

1. To examine the perceptions of private and public sector practitioners regarding change management at the tertiary level.

2. To investigate the difference between change management phases at the tertiary level.

\section{Conceptual Framework of the Study}

The conceptual framework is based on the assessment of the most recent Fullan's (2016) Model levels, through specified variables of change, the study was intended to compare the levels of Fullan (2016) in the context of the process of change management at universities of public and private sectors in Punjab.

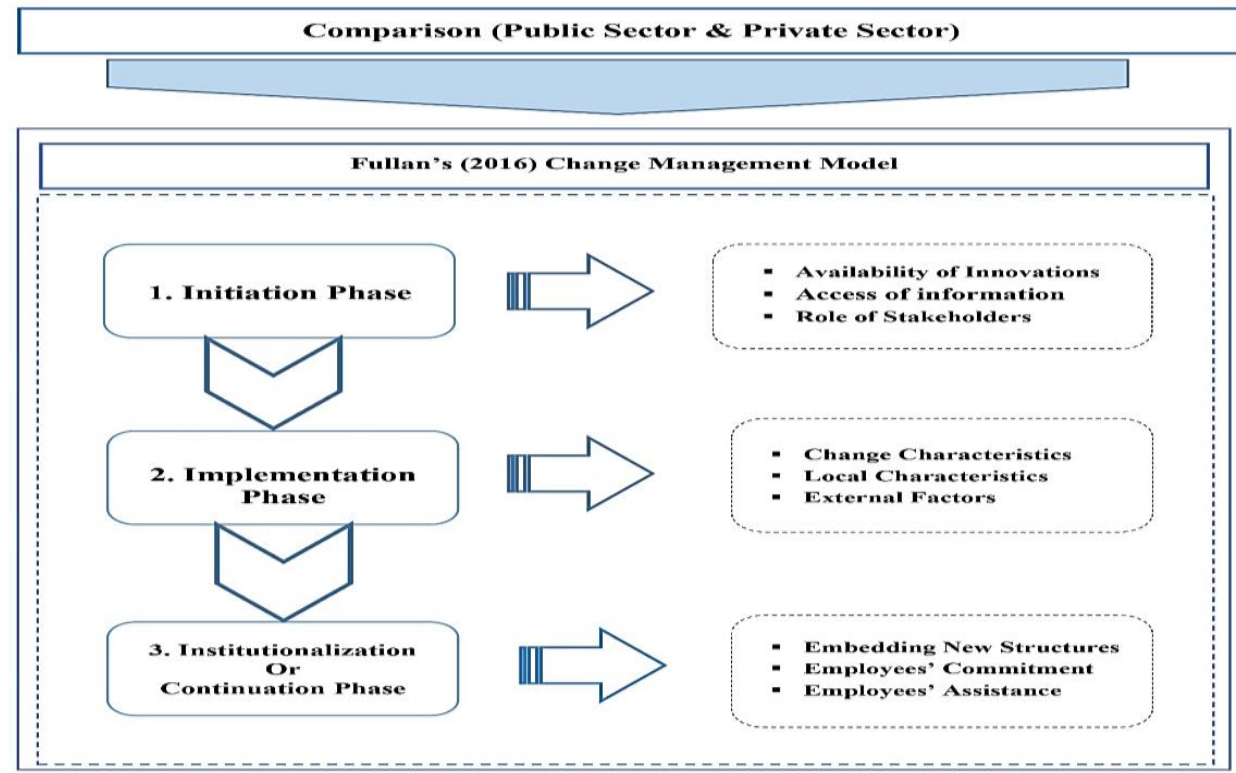

Figure 2: Conceptual Framework of the Study 


\section{METHODOLOGY}

The present study was descriptive in nature in which quantitative design was used.

\section{The population of the Study}

The population of the study comprised 2685 faculty members from departments of social sciences. The population count was taken from websites of universities and department officials were contacted where necessary. To compare the change management strategies, the population was divided into two major strata of public and private sector universities of Punjab.

\section{Sample and Sampling Technique}

According to Cohen, Manion \& Morrison's (2013) sample table, the sample size against the population more than 2,500 is 536 at a $4 \%$ confidence interval. Through this process, approximately $20 \%$ faculty from each stratum were selected as a sample. Gay (1987) suggests that $10 \%$ of large and $20 \%$ of small population as minimum may be selected. Table 1 shows the sampling details.

Table 1. Sample of the Study

\begin{tabular}{ccc}
\hline Sector & Social Sciences & Sample $(\sim 20 \%)$ \\
\hline Public Sector & 1578 & 315 \\
Private Sector & 1107 & 221 \\
Total & $\mathbf{2 6 8 5}$ & $\mathbf{5 3 6}$ \\
\hline
\end{tabular}

\section{Research Instrument}

Researchers developed a questionnaire based on Fullans' Educational Change Model (2016) consists of 54 items which are divided into three phases namely Initiation Phase, Implementation Phase, and Continuation Phase.

To find out the validity and reliability of the instrument, the validity of the instrument was ensured through experts' opinion. Researchers conducted a pilot study with 100 participants those were not included in the actual sample. The instrument was found reliable as the value of Cronbach's Alpha Coefficient was 0.78. Reliability of the subscales initiation, implementation, and continuation were $0.78,0.84$, and 0.75 .

\section{Data Collection}

Data has been collected through a web-based questionnaire (to avoid Covid-19 related risks) while considering the health SOPs. A web-based link to the questionnaire was sent to the respondents because most of the respondents were conducting online classes from home, a further few extra webbased links were forwarded and followed up to ensure the total size of the sample. The questionnaire was filled properly by respondents.

\section{Data Analysis}

After data collection, the data from quantitative data were tabulated and analyzed statistically through Mean and t-test.

\section{RESULTS}

Table 2. Contribution of Change Management Phases at higher education level

\begin{tabular}{lccc}
\hline Phases of Change Management & N & Mean & SD \\
\hline Initiation Phase & 536 & 3.34 & 0.71 \\
Implementation Phase & 536 & 3.49 & 0.87 \\
Continuation Phase & 536 & 3.52 & 0.76 \\
Overall & $\mathbf{5 3 6}$ & $\mathbf{3 . 6 3}$ & $\mathbf{0 . 6 8}$ \\
\hline
\end{tabular}

Table no. 2 describes faculty perception regarding the contribution of change management phases at the higher education level. In the first phase of change management i.e. 'initiation phase', the respondents indicate that the administration focuses on the initiation phase (Mean score $=3.34$ ), whereas on second phase i.e. implementation phase, respondents indicate that the administration 
focuses carefully on the implementation phase (Mean score $=3.49$ ) when inquired faculty view about the continuation phase, the respondents claim that the institution focuses on the continuation of change after implementing it (Mean score $=3.52)$. Overall mean score $($ Mean $=3.63)$ indicates that administrators in all institutions focus on all change management phases effectively.

Table 3. Change Management (Sector wise comparison)

\begin{tabular}{cccccccc}
\hline Variable & $\begin{array}{c}\text { Group } \\
\text { (Sector) }\end{array}$ & $\mathbf{N}$ & Mean & $\boldsymbol{t}$ & $\boldsymbol{d f}$ & $\begin{array}{c}\text { Sig } \\
\text { (2-tailed) }\end{array}$ & Cohen's d \\
\hline Change & Public & 315 & 3.72 & 3.89 & 534 & .00 & 0.38 \\
Management & Private & 221 & 3.44 & & \\
\hline
\end{tabular}

Table 3 shows $t$ value (3.89) is statistically significant at a 0.05 level of significance. It proves that was significant difference found between the public and private sectors. The mean score of the public sector (Mean score $=3.72$ ) is higher as compared to the mean score of the private sector (Mean score $=3.44)$. The effect size was found 0.38 which shows the moderate effect size between the two means.

A commonly used interpretation is to refer to effect sizes as small $(d=0.2)$, medium $(d=$ $0.5)$, and large $(\mathrm{d}=0.8)$ based on benchmarks suggested by Cohen $(1988)$.

Table 4. Phases of Change Management (Sector wise comparison)

\begin{tabular}{cccccccc}
\hline $\begin{array}{c}\text { Phases of Change } \\
\text { Management }\end{array}$ & $\begin{array}{c}\text { Group } \\
\text { (Sector) }\end{array}$ & $\mathbf{N}$ & Mean & $\boldsymbol{t}$ & $\boldsymbol{d f}$ & $\begin{array}{c}\text { Sig } \\
\text { (2-tailed) }\end{array}$ & Cohen's d \\
\hline Initiation & Public & 315 & 3.52 & 2.75 & 534 & .00 & 0.25 \\
& Private & 221 & 3.34 & & & & \\
Implementation & Public & 315 & 3.66 & 4.68 & 534 & .00 & 0.40 \\
& Private & 221 & 3.43 & & & & \\
Continuation & Public & 315 & 3.75 & 3.44 & 534 & .00 & 0.29 \\
\hline
\end{tabular}

Table 4 shows that in the first phase of change management the $t$ value (2.75) is statistically significant at a 0.05 level of significance. It shows that there was significant difference found between public sector and private sector respondents at the 'initiation phase'. Public sector response (Mean score $=3.52$ ) was found better as compared to the private sector faculty respondents (Mean score $=$ 3.34). The effect size was found 0.25 that shows the small effect size between the two means. In the second phase, the $t$ value (4.68) is statistically significant at a 0.05 level of significance. It shows that there was significant difference found between public and private sector respondents at the 'implementation phase'. The mean score of public sector respondents (Mean score $=3.66$ ) was found better as compared to the mean score of private sector respondents (Mean score $=3.43$ ). The effect size was found 0.40 that shows the moderate effect size between the two means. In the third phase, the $t$ value (3.44) is statistically significant at a 0.05 level of significance. It shows that there was significant difference found between the response of the public sector and the private sector at the 'continuation' phase. The mean score of public sector respondents (Mean score $=3.75$ ) was found better as compared to the mean score of private sector respondents (Mean score $=3.51$ ). The effect size was found 0.29 that shows the small effect size between the two means.

\section{DISCUSSION}

Results revealed that faculty members believe that three dimensions of change management initiation, continuation, and most importantly the implementation are being practiced in their institutions. These findings are aligned with the study conducted by Naz \& Murad (2019) on 200 teachers from public and private sector universities of Lahore, Pakistan to check the effectiveness of innovative teaching as a factor of educational change, findings of the study revealed that there exists a huge gape to cope with the rapid educational change at higher education. Faculty members are ready to accept change but they seem comfortable while teaching through conventional methods.

Results are also found significant for faculty members in the process of change. A study conducted by Habib, Khalil \& Zahid (2021) determine and report the sustainability in the higher 
education sector of Pakistan. One particular aspect of the study is integrating sustainability into operations which shows very encouraging results i.e. HEIs in Pakistan showed positive results in operational sustainability that also include sustainability in the educational change process.

The results are in line with the study conducted by Suraeva \& Plaksina (2018) which shows that educational changes in the Russian HEIs are separated into four ways which include changes in educational activities, innovation, research, and entrepreneurial management. The present study aimed to help the field by implementing the Fullan change management model. Hubers (2020), found that there is increasing demand for more knowledge about sustainable educational change. McGrath (2017) found that change agents at higher education level often lack systematic approaches to change, they feel difficulty doing things here and now.

Significant differences were found regarding the self-reported change management in the public and private sectors. This finding is consistent with the survey conducted by McGrath et al. (2016) on higher education change agents in which significant differences were found within change agents belonging to different sectors. In the private sector change agents or administrators always encounter resistance as compared to the government sector. Davies (2015) also found there is a significant difference among sectors regarding change management.

\section{CONCLUSION}

The study concluded that the tertiary institutions mainly focus on the continuation phase while dealing with change management. Comparison of public and private sector shows that public sector institutions were found better while dealing with change management strategies. Therefore, public sector institutions seemed to adopt change management at a higher level and more efficiently than private institutions. In-depth, results showed that institutions mainly differ at the implementation phase with a larger effect size.

\section{RECOMMENDATIONS}

The desire to reform the system to cope up with 21 st-century challenges is a positive sign for higher education in Pakistan. The data indicated that private institutions face issues in implementing reforms according to the streamlining of Fullan's (2016) model. Therefore, the study recommended improved communication and coordination of stakeholders while implementing the reform both in the public and private sectors. The study also recommended using a research-based approach while initiating and implementing the educational reform. In the future, researchers can extend the investigation to different geographical locations and taking data from more institutions. It is further recommended to use multiple research frameworks designs to enhance the understanding of more change initiatives and implementations.

\section{REFERENCES}

Brix, J., \& Peters, L. S. (2015). Exploring an innovation project as a source of change in organization design. Journal of Organization Design, 4(1), 29-43. https://doi.org/10.7146/jod.17574

Cohen, L., Manion, L., \& Morrison, K. (2013). Research methods in education. Routledge.

Cummings, S., Bridgman, T., \& Brown, K. G. (2016). Unfreezing change as three steps: Rethinking Kurt Lewin's legacy for change management. Human Relations, 69(1), 33-60. https://doi.org/10.26686/wgtn.12735971.v1

Da Veiga, A. (2018). An approach to information security culture change combining ADKAR and the ISCA questionnaire to aid the transition to the desired culture. Information \& Computer Security. https://doi.org/10.1108/ics-08-2017-0056

Dana, B. G., Mukaj, L., \& Vishkurti, M. (2016). Creating a model culture of management change. Annals of the University of Oradea, Economic Science Series, 25(1), 871-880.

Davies, J. (2015). Exploring issues in change management: Developing a systems perspective on the management of learning and teaching initiatives. International Journal of Higher Education Management, 2(1).

Dawson, P. (2019). Reshaping change: A processual perspective. Routledge.

Doppelt, B. (2017). Leading change toward sustainability: A change-management guide for business, government, and civil society. Routledge.

Finnan, C \& Levin, H. (2000) Changing school cultures (pp 87- 98). In H. Altricher and J. Elliot 
(eds.) Images of Educational Change. Open University Press.

Fullan, M. \& Levin, B. (2009). The Fundamentals of Whole-System Reform: A Case Study From Canada. Education Week 28 (35): 30-31.

Fullan, M. (2016). The New Meaning of Educational Change (5th Ed., p. 56), NY.

Ghavifekr, S., Afshari, M., Siraj, S., \& Razak, A. Z. A. (2017). Managing change in educational organization: a conceptual overview. MOJEM: Malaysian Online Journal of Educational Management, 1(1), 1-13.

Habib, M. N., Khalil, U., Khan, Z., \& Zahid, M. (2021). Sustainability in higher education: what is happening in Pakistan?. International Journal of Sustainability in Higher Education. https://doi.org/10.1108/ijshe-06-2020-0207

Hayes, J. (2018). The theory and practice of change management. Palgrave.

Hornstein, H. A. (2015). The integration of project management and organizational change management is now a necessity. International Journal of Project Management, 33(2), 291298. https://doi.org/10.1016/j.ijproman.2014.08.005

Hubers, M. D. (2020). Paving the way for sustainable educational change: Reconceptualizing what it means to make educational changes that last. Teaching and teacher education, 93, 103083. https://doi.org/10.1016/j.tate.2020.103083

McGrath, C. (2017). What we talk about when we talk about change: a study of change practice and change agency in higher education. Ph.D. Thesis. Karolinska Institutet

McGrath, C., Barman, L., Stenfors-Hayes, T., Roxå, T., Silén, C., \& Laksov, K. B. (2016). The ebb and flow of educational change: Change agents as negotiators of change. Teaching \& Learning Inquiry, 4(2), 1-14. https://doi.org/10.20343/teachlearninqu.4.2.9

Miles, M. B., \& Huberman, A. M. (1994). Qualitative data analysis: An expanded sourcebook (2nd ed.). Thousand Oaks, CA: Sage Publications.

Naz, F., \& Murad, H. S. (2019). Innovative teaching: An effective ingredient for educational change at the University level. Pakistan Journal of Education, 36(2), 115-135. https://doi.org/10.30971/pje.v36i2.691

Ramos, T. B., Caeiro, S., Van Hoof, B., Lozano, R., Huisingh, D., \& Ceulemans, K. (2015). Experiences from the implementation of sustainable development in higher education institutions: Environmental Management for Sustainable Universities. Journal of Cleaner Production, 106, 3-10. https://doi.org/10.1016/j.jclepro.2015.05.110

Razzaq, J. (2012).The management of educational change in Pakistani educational institutions. Ph.D. thesis. The University of Glasgow.

Razzaq, J., \& Forde, C. (2014). The management of large-scale change in Pakistani education. School Leadership \& Management, 34(3), 299-316. https://doi.org/10.1080/13632434.2014.905467

Salawana, B. (2019). Managing Educational Changes and School Leadership: Issues and Challenges. In The 2nd International Conference on Sustainable Development \& Multi-Ethnic Society (pp. 187-191). Redwhite Press.

Sawitri, H. S. R., Wahyuni, S., Suprapti, A. R., \& Mayasari, D. (2015). Readiness of Employees for Organizational Change. WCBM 2015.

Scott, D., Terano, M., Slee, R., Husbands, C., \& Wilkins, R. (2016). Policy transfer and educational change. Sage.

Suraeva, M. O., \& Plaksina, I. A. (2018). Systematization of drivers of change in the higher education system of the Russian Federation. Problems and Perspectives in Management, 16(2), 56-63. https://doi.org/10.21511/ppm.16(2).2018.06

Vähäsantanen, K. (2015). Professional agency in the stream of change: Understanding educational change and teachers' professional identities. Teaching and teacher education, 47, 1-12. https://doi.org/10.1016/j.tate.2014.11.006

Verhulst, E., \& Lambrechts, W. (2015). Fostering the incorporation of sustainable development in higher education. Lessons learned from a change management perspective. Journal of Cleaner Production, 106, 189-204. https://doi.org/10.1016/j.jclepro.2014.09.049 